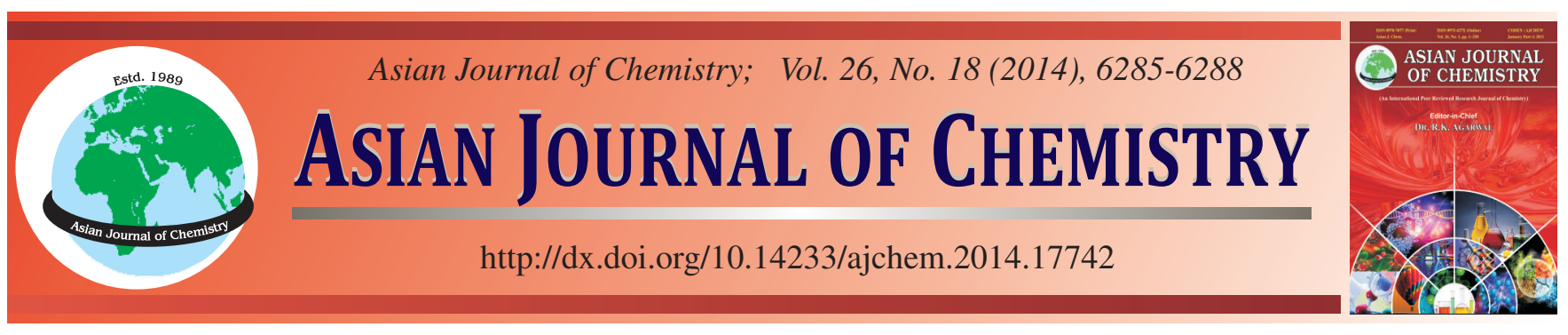

\title{
Effect of Solvents on Extraction and Adsorption of Natural Dyes Extracted from Cordyline fruticosa and Hylocereus polyrhizus
}

\author{
Mahmoud A.M. Al-Alwani ${ }^{1,3, *}$, Abu Bakar Mohamad ${ }^{1}$, Abdul Amir H. Kadhum ${ }^{1}$ and N.A. Ludin ${ }^{2}$
}

${ }^{1}$ Department of Chemical and Process Engineering, Faculty of Engineering and Built Environment, Universiti Kebangsaan Malaysia, 43600 Bangi, Selangor, Malaysia

${ }^{2}$ Solar Energy Research Institute (SERI), Universiti Kebangsaan Malaysia, 43600 Bangi, Selangor, Malaysia

${ }^{3}$ Department of Biology, College of Education for Pure Sciences/Ibn Al-Haitham, University of Baghdad, Baghdad, Iraq

*Corresponding author: Tel: +60 182862623; E-mail: mamash73@yahoo.com

Different solvents, such as $n$-hexane, ethanol, acetonitrile, chloroform, ethyl-ether, methanol and water, were used to extract dyes from the leaves of Cordyline fruticosa and the fruits of Hylocereus polyrhizus, to be used as sensitizers for dye-sensitized solar cells. The dyes extracted from these species contained chlorophyll, betanin and betaxanthin. Methanol and water were shown to be the best solvents according to the highest absorbance obtained from the dye solutions of $C$. fruticosa and $H$. polyrhizus, respectively. The photochemical performance of dyes extracted from $C$. fruticosa with different solvents mixed with $\mathrm{TiO}_{2}$ indicated that the main effectual solvent was a mixture of methanol and water, in a ratio of 3:1. Meanwhile, water was demonstrated to be the most effective solvent for the $H$. polyrhizus dye adsorption on $\mathrm{TiO}_{2}$ particles. This study expects the good absorption efficiency of $\mathrm{TiO}_{2}$ with natural dyes to be used for future applications in dye-sensitized solar cell devices.

Keywords: Natural dyes, Solvents, Dye-sensitized solar cells, Cordyline fruticosa, Hylocereus polyrhizus.

\section{INTRODUCTION}

Dye-sensitized solar cells, developed by O'Regan and Grätzel $^{1}$ as a device used for the conversion of sunlight into electricity, are based on the sensitization of semiconductor's wide band gap. The performance of dye-sensitized solar cells mainly depends on the dyes used as sensitizers, which play a key role in absorbing sunlight and converting solar energy into electric energy ${ }^{2}$. The main parameters that determine the conversion efficiency of cells include (i) the absorption spectrum of the dye and (ii) the anchorage of the dye to the surface of $\mathrm{TiO}_{2}$ nanocrystalline ${ }^{3}$.

Natural pigments have been considered as promising alternative sensitizer dyes for dye-sensitized solar cell, because of low cost, simple preparation technique, easy availability, complete biodegradation, applied without further purification, environmental friendly; in addition to its reduced high cost of noble metals and chemical synthesis ${ }^{4,5}$. The structure of the natural pigment used as a sensitizer determines the strength of being attached to the $\mathrm{TiO}_{2}$ surface. If the dye's structure has hydroxyl or carboxyl functional groups, the dye binds strongly to the $\mathrm{TiO}_{2}$ surface ${ }^{6}$. The interaction between $\mathrm{TiO}_{2}$ and the dye leads to excited electron transfer from the dye molecules to the conduction band of the $\mathrm{TiO}_{2}$ semiconductor ${ }^{7}$. The highest efficiency of dye-sensitized solar cell, sensitized by ruthenium polypyridyl complexes absorbed ${ }^{8}$ on $\mathrm{TiO}_{2}$, reached 11 to $12 \%$. However, ruthenium complexes contain a heavy metal, which is undesirable from the point of view of cost and the environment ${ }^{9}$. However, alternatively, natural dyes can be used for the same purpose, due to their low cost, non-toxicity, availability and complete biodegradation ${ }^{10}$.

The natural dyes found in leaves, flowers, fruits and seeds, can be extracted using simple procedures. Several natural dyes have been used as sensitizers in dye-sensitized solar cells, such as chlorophyll ${ }^{11}$, betalains ${ }^{12}$, a carotenoid ${ }^{13}$, anthocyanin ${ }^{14}$, flavonoids ${ }^{15}$ and tannin ${ }^{16}$. Betalains, which are present in plants of the caryophyllales order, are also found in some higher fungi. Its water-soluble pigment is responsible for the visible part of the solar spectrum ${ }^{17}$. Betalains are divided into betacyanins (red-violet) and betaxanthins (yellow-orange $)^{18}$. Betalains have the necessary functional group $(-\mathrm{COOH})$ to facilitate the link to the surface of the dye-sensitized solar cell semiconductor ${ }^{19}$. Generally, most of the reports that used betalain compounds as sensitizers for dye-sensitized solar cells, utilized Beta vulgaris ${ }^{20}$, Sicilian prickly pear fruit ${ }^{21}$ and Bougainvillea spectabilis $^{19}$, as their betalain compound sources.

Chlorophyll is a green pigment found in the leaves of most green plants, algae and cyanobacteria. Six different types 
of chlorophyll pigments exist; the most common of which is chlorophyll $\mathrm{a}^{22}$. Chlorophyll absorbs light from red, blue and violet wavelengths and gets its colour by reflecting green ${ }^{23}$. Chlorophyll has two main absorption peaks in the visible region, at wavelengths 420 and $660 \mathrm{~nm}$. Different kinds of organic solvents are used to extract natural pigments from different organs of plants. These solvents affect the absorption spectra of the dyes, as well as the effect on banding between dyes and the $\mathrm{TiO}_{2}$ surface ${ }^{24}$.

In this current study, the authors selected two tropical plant species grown in Malaysia, namely Cordyline fruticosa and Hylocereus polyrhizus (dragon fruit). They used different solvents to extract the natural pigments from the leaves of $C$. fruticosa and the fruits of $H$. polyrhizus. After identifying the optimum solvent to extract dyes from these two species, the best solvent and the optimum ratio of solvent for dye extraction was investigated using UV-visible spectroscopy.

\section{EXPERIMENTAL}

Extraction of natural dyes: The leaf extracts of $C$. fruticosa were obtained according to the following steps: after cleaning $C$. fruticosa leaves were dried at $40^{\circ} \mathrm{C}$ in an oven. They were crushed into a fine powder using a grinder (Mulry function disintegrator SY-04); $15 \mathrm{~g}$ of the powder was then put into $150 \mathrm{~mL}$ of six different solvents and left for one week (at room temperature), in a dark condition. The extract solution was then filtered using filter paper (NICE, $12.5 \mathrm{~cm}, 102$ Qualitative). Finally, the dye solution was concentrated using a rotary evaporator (Yamato RE 600 ) at $50^{\circ} \mathrm{C}$ for $3 \mathrm{~h}$. The skins of the dragon fruits (H. polyrhizus) were manually separated from the pulp. The pulp was then cut into small pieces (of 15 g) and immersed in $150 \mathrm{~mL}$ of four different solvents for $24 \mathrm{~h}$ (at room temperature) in a dark condition. Soiled residues were filtrated using filter paper, The filtrate was then concentrated using a rotary evaporator at $40{ }^{\circ} \mathrm{C}$ for $3 \mathrm{~h}$. The absorption spectra of the studied dye extracts were measured using a UVvisible spectrophotometer (Perkin Elmer, Lambda35). The structures of the isolated dyes were confirmed using Fourier transmission infrared (FTIR) and the spectra was recorded using a Thermo Scientific, NICOLET 6700 spectrometer.
Preparation of dye- $\mathrm{TiO}_{2}$ solutions: The concentrated C. fruticosa extract was dissolved using methanol mixed with water at various ratios from 1:4 to 4:1. The dye solutions were then mixed with $1 \mathrm{~g}$ of $\mathrm{TiO}_{2}$. The $H$. polyrhizus dye extract was dissolved in water and then mixed with $1 \mathrm{~g} \mathrm{TiO}_{2}$. Finally, the dye solutions, which were mixed with $\mathrm{TiO}_{2}$, were measured using a UV-visible spectrophotometer.

\section{RESULTS AND DISCUSSION}

Absorption of natural dyes in different solvents: Fig. 1 shows the absorption spectrum of $C$. fruticosa leaf extracts in methanol, $n$-hexane, ethanol, chloroform, acetonitrile and ethyl-ether. The extracted $C$. fruticosa shows an absorption visible range of 630 to $700 \mathrm{~nm}$. Three main peaks were observed at approximately 530, 605 and $660 \mathrm{~nm}$. The absorption peaks of dyes in this study were similar to the absorption spectrum of chlorophyll (Fig. 2a) shown in previous reports ${ }^{25,26}$. In comparison, extraction using methanol showed the highest peak of absorption spectra of $C$. fruticosa dyes. The band is solvent sensitive, with a local maximum shifted toward higher from acetonitrile to methanol of $C$. fruticosa leaf extracts.

Fig. 3 shows the UV-visible absorption spectrum of $H$. polyrhizus fruits, extracted in water, methanol, ethanol and mixed ethanol-water (at a ratio of $1: 1$ ). In the visible region,

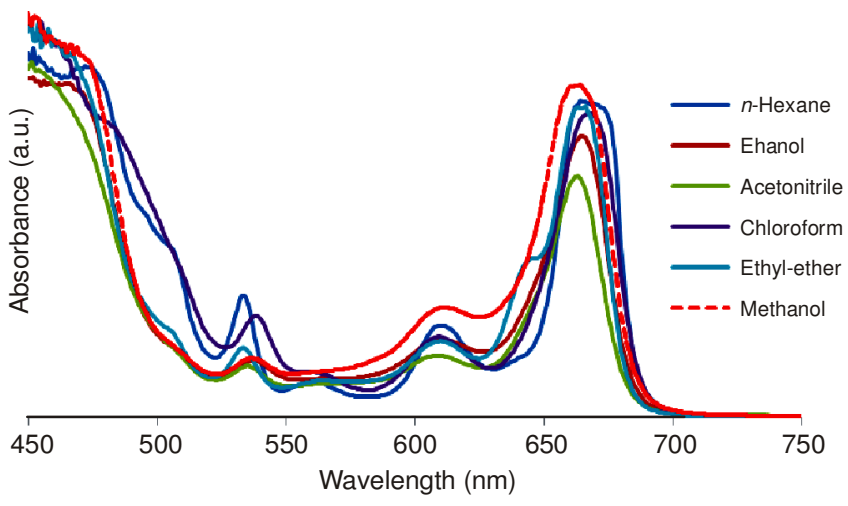

Fig. 1. UV-visible absorption spectra of extracts using different solvents from $C$. fruticosa

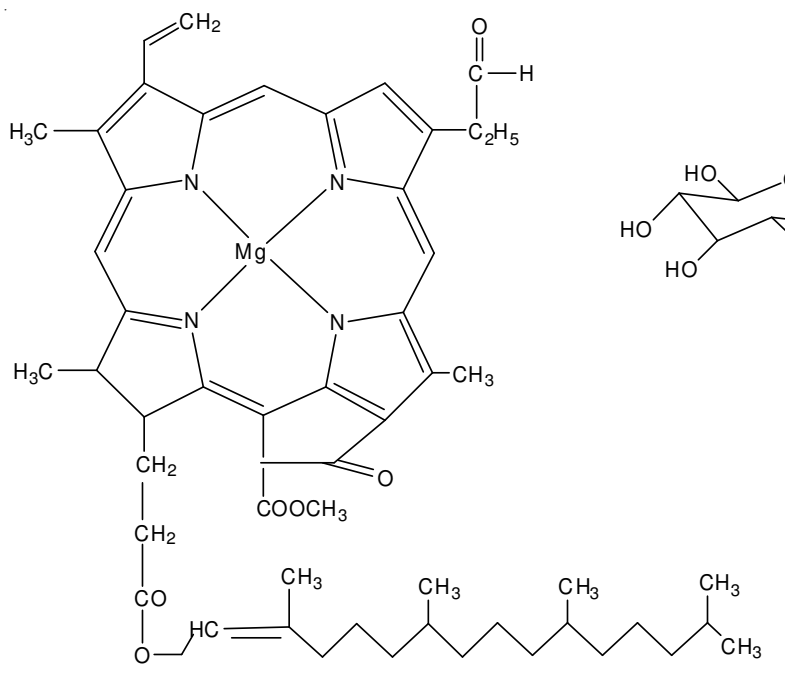

(a)<smiles>COC1=CC2=C(CC1O)N(C=CC1=CC(=O)N[C@H](C(=O)O)C1)[C@H](C(=O)O)C2</smiles><smiles>[R5][NH+]=CC=C1C=C(C(=O)O)N[C@H](C(=O)O)C1</smiles>

(b)

(c)

Fig. 2. General structure of (a) chlorophyll, (b) Betanin and (c) Betaxanthin 


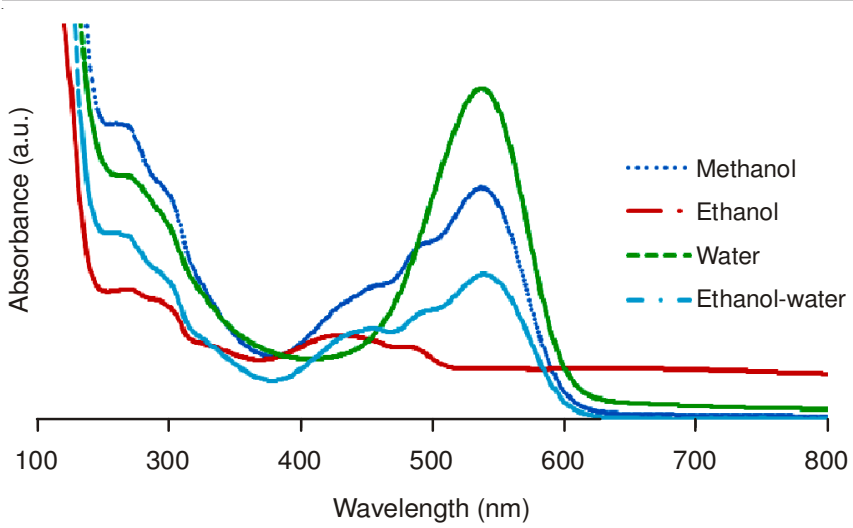

Fig. 3. UV-visible absorption spectra of the extracts using different solvents from $H$. polyrhizus

the aqueous solution of $H$. polyrhizus dye showed a main peak at $530 \mathrm{~nm}$, which was associated with the existence of betanin (Fig. 2b). Meanwhile, the dye solutions that used methanol, ethanol and mixed ethanol/water, showed two peaks at 530 $\mathrm{nm}$ (betanin) and $480 \mathrm{~nm}$, which was ascribed to the presence of betaxanthins (Fig. 2c). The absorption spectrum for extraction using water showed the most intense curves and the highest peak; compared to dyes extracted using other solvents. These results are consistent with the results reported by previous workers ${ }^{27,28}$.

FTIR study of dye's structures: The recorded FTIR spectra of the dyes obtained from $C$. fruticosa leaves and H. polyrhizus fruits are shown in Fig. 4a,b. The structures of the isolated dyes, which were confirmed by their FTIR spectra, were extracted using the optimum solvent; which had different structures according to the type of source. The FTIR functional groups of dyes were indicated as (a) $C$. fruticosa and (b) $H$. polyrhizus. The sharper peak, which contained three heads belonging to the $\mathrm{C}=\mathrm{C}$ group, was more clearly observed in $C$. fruticosa than $H$. polyrhizus.

However, the $\mathrm{C}=\mathrm{O}$ group appears in the $1739 \mathrm{~cm}^{-1}$ wavelength and $\mathrm{CH}_{3}$ group at $1456 \mathrm{~cm}^{-1}$. The presence of the $\mathrm{C}-\mathrm{O}$ group at around $1060 \mathrm{~cm}^{-1}$, as a strong peak, was indicated higher in the dye. The aldehydes were found between the 879 to $721 \mathrm{~cm}^{-1}$ wavelength, due to the base of the natural organic dyes. At the same time, the $H$. polyrhizus dye was shown to be similar to the functional groups of $\mathrm{OH}, \mathrm{C}=\mathrm{C}$ and $\mathrm{C}-\mathrm{O}$, as indicated from the wavelength of absorbance. Therefore, two groups of $\mathrm{C}=\mathrm{O}$ and $\mathrm{OH}$, of the aromatic compound, were obtained at different wavelengths of 1635 and $1416 \mathrm{~cm}^{-1}$, respectively. Accordingly, the difference between the dyes was confirmed by the absorbance, as shown in Fig. 3. The absorbance for $C$. fruticosa was different to that of $H$. polyrhizus.

\section{Absorption spectra of natural dyes adsorbed on $\mathrm{TiO}_{2}$ :}

Fig. 5 shows the absorbance spectra of dye extracted from C. fruticosa leaves, loaded onto a surface, using methanol and mixtures of methanol and water, at eight ratios ranging from 1:4 to 4:1 (methanol-water). The absorption of $C$. fruticosa dyes onto $\mathrm{TiO}_{2}$ increased alongside the methanol: water mixture at a ratio of $3: 1$, compared to methanol mixtures at other ratios. Fig. 6 shows the absorption spectra of $H$. polyrhizus fruit dye onto the $\mathrm{TiO}_{2}$ surface using methanol, water, methanolwater and ethanol-water. The absorption spectra of $\mathrm{TiO}_{2}$ loaded
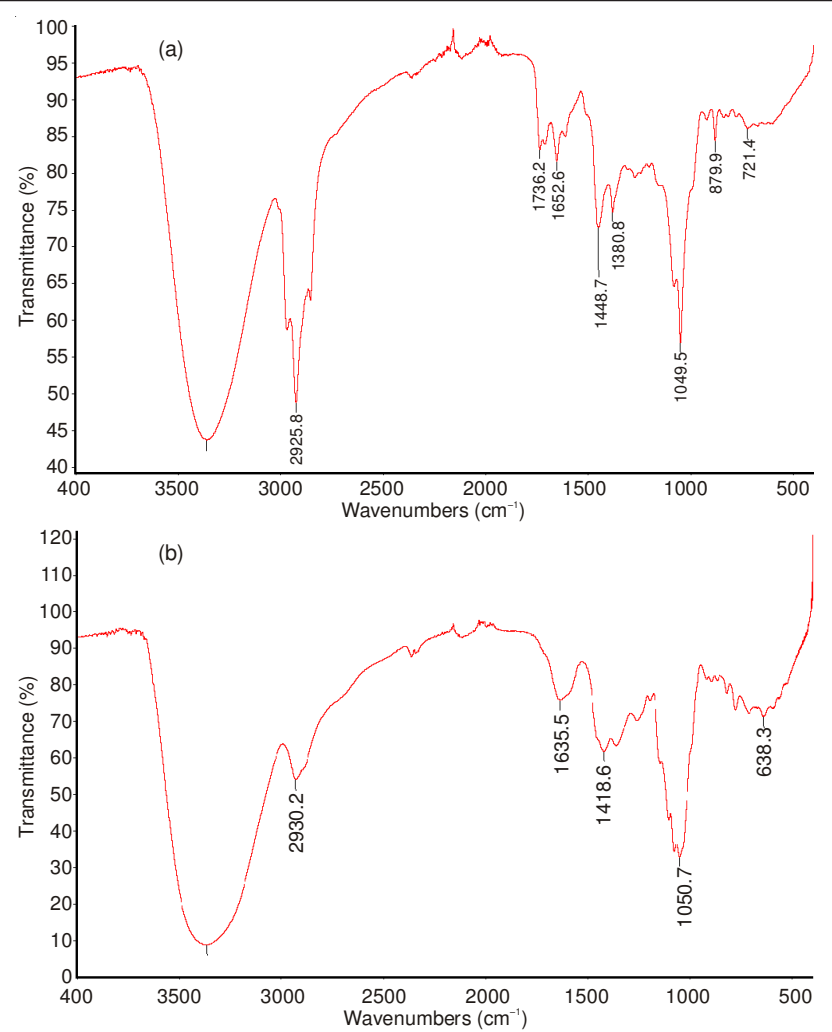

Fig. 4. FTIR spectra for dyes obtained from (a) C. fruticosa and (b) H. polyrhizus

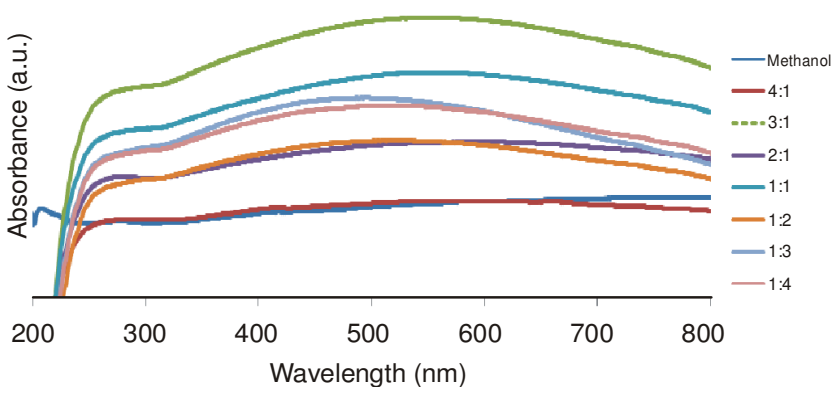

Fig. 5. Absorption spectra of $C$. fruticosa leaf dyes adsorbed onto $\mathrm{TiO}_{2}$ under different ratios of methanol to water mixtures

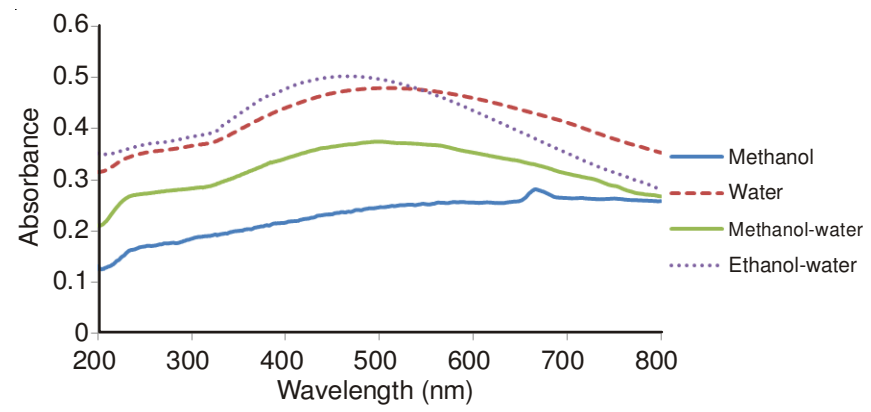

Fig. 6 Absorption spectra of $H$. polyrhizus leaf dyes adsorbed onto $\mathrm{TiO}_{2}$ using different solvents

with $H$. polyrhizus dyes increased alongside the water and ethanol-water ratios. The dye's ability to carry attachments of carboxyl or hydroxyl groups and types of solvent, controlled the amount of dye that was adsorbed onto the molecules ${ }^{29}$ of $\mathrm{TiO}_{2}$.

These current results might attribute to the fact that the dye extracted from $C$. fruticosa had a good solubility in mixtures 
of methanol-water at a ratio ${ }^{30}$ of $3: 1$. This could be due to the higher amount of dye that was adsorbed onto the particles of the semi conductive $\mathrm{TiO}_{2}$, which enhanced the absorption spectrum of the dye with $\mathrm{TiO}_{2}$. In addition, more than optimum ratio of methanol-water $(3: 1)$ produced a higher polarity between the dye molecules and the surface of the $\mathrm{TiO}_{2}$, which increased the repulsing effect between them ${ }^{19}$.

\section{Conclusion}

This study used two plant species, which grow in Malaysia, for the extraction of dyes from their leaves and fruits, namely: $C$. fruticosa and $H$. polyrhizus, respectively. The results show that chlorophyll and betalains dyes were soluble in different solvents (i.e., water, methanol, $n$-hexane, ethanol, chloroform and acetonitrile). The results identified that methanol and water were the best solvents to use for dye extraction from the leaves of $C$. fruticosa and the fruits of $H$. polyrhizus, respectively. Moreover, the $\mathrm{TiO}_{2}$ nanoparticles, coated with chlorophyll and betalains dyes, had a higher absorption spectra when the ratio of methanol and water was at 3:1 and water used in different solutions.

\section{ACKNOWLEDGEMENTS}

The authors thank Universiti Kebangsaan Malaysia (Research Grant UKM DIP-2012-02) and Solar Energy Research Institute (SERI) for their financial support. One of the author, Mahmoud A. M. Al-Alwani, also thank the College of Education for Pure Science-Ibn Al-Haitham, University of Baghdad, Baghdad, Iraq.

\section{REFERENCES}

1. B. O'Regan and M. Gratzel, Nature, 353, 737 (1991).

2. H. Zhou, L. Wu, Y. Gao and T. Ma, J. Photochem. Photobiol. Chem., 219, 188 (2011).

3. E.M. Abdou, H.S. Hafez, E. Bakir and M.S.A. Abdel-Mottaleb, Spectrochim. Acta A, 115, 202 (2013).

4. K. Sinha, P.D. Saha and S. Datta, Dyes Pigments, 94, 212 (2012)

5. S. Kishimoto, T. Maoka, K. Sumitomo and A. Ohmiya, Biosci. Biotechnol. Biochem., 69, 2122 (2005).
6. N.A. Ludin, A.M. Al-Alwani Mahmoud, A. Bakar Mohamad, A.A.H. Kadhum, K. Sopian and N.S. Abdul Karim, Renew. Sustain. Energy Rev., 31, 386 (2014).

7. M.R. Narayan, Renew. Sustain. Energy Rev., 16, 208 (2012).

8. R. Buscaino, C. Baiocchi, C. Barolo, C. Medana and M. Gratzel, Chem. Acta, 361, 798 (2008).

9. K. Wongcharee, V. Meeyoo and S. Chavadej, Sol. Energy Mater. Sol. Cells, 91, 566 (2007)

10. S. Furukawa, H. Iino, T. Iwamoto, K. Kukita and S. Yamauchi, Thin Solid Films, 518, 526 (2009).

11. P. Luo, H. Niu, G. Zheng, X. Bai, M. Zhang and W. Wang, Spectrochim. Acta A Mol. Biomol. Spectrosc., 74, 936 (2009).

12. G. Calogero, J.-H. Yum, A. Sinopoli, G. Di Marco, M. Grätzel and M.K. Nazeeruddin, Sol. Energy, 86, 1563 (2012).

13. H. Zhou, L. Wu, Y. Gao and T. Ma, J. Photochem. Photobiol. Chem., 219, 188 (2011).

14. M. Alhamed, A.S. Issa and A.W. Doubal, J. Electron Devices, 16, 1370 (2012).

15. K. Sutthanut, B. Sripanidkulchai, C. Yenjai and M. Jay, J. Chromatogr. A, 1143, 227 (2007).

16. M. Kamel, R.M. El-Shishtawy, B.M. Yussef and H. Mashaly, Dyes Pigments, 65, 103 (2005).

17. L.C. Goncalves, P.R.R. Tonelli, P. Bagnaresi, R.A. Mortara, A.G. Ferreira and E.L. Bastos, PLoS ONE, 8, e53874 (2013).

18. D. Strack, T. Vogt and W. Schliemann, Phytochemistry, 62, 247 (2003).

19. A.R. Hernandez-Martinez, M. Estevez, S. Vargas, F. Quintanilla and R. Rodriguez, Int. J. Mol. Sci., 12, 5565 (2011).

20. D. Zhang, S.M. Lanier, J.A. Downing, J.L. Avent, J. Lum and J.L. McHale, J. Photochem. Photobiol. Chem., 195, 72 (2008).

21. G. Calogero, G. Di Marco, S. Cazzanti, S. Caramori, R. Argazzi, A. Di Carlo and C.A. Bignozzi, Int. J. Mol. Sci., 11, 254 (2010).

22. X.-F. Wang, J. Xiang, P. Wang, Y. Koyama, S. Yanagida, Y. Wada, K. Hamada, S.- Sasaki and H. Tamiaki, Chem. Phys. Litter, 408, 409 (2005).

23. W.H. Lai, Y.H. Su, L.G. Teoh and M.H. Hon, J. Photochem. Photobiol. Chem., 195, 307 (2008).

24. K.A. Aduloju, B.S. Mohamed and J. Simiyu, Fundamental J. Modern Physics, 1, 261 (2011).

25. G.R.A. Kumara, S. Kaneko, M. Okuya, B. Onwona-Agyeman, A. Konno and K. Tennakone, Sol. Energy Mater. Sol. Cells, 90, 1220 (2006).

26. H.I. Scheer, in eds.: B.R. Green and W.W. Parson, Light-Harvesting Antennas in Photosynthesis, Dordrecht: Kluwer Academic Publishers, p. 513 (2003).

27. G. Sepulveda-Jimenez, P. Rueda-Benitez, H. Porta and M. Rocha-Sosa, Physiol. Mol. Plant Pathol., 64, 125 (2004).

28. H.M.C. Azeredo, Int. J. Food Sci. Technol., 44, 2365 (2009).

29. H. Hafez and L. Zhang, Nanotechnol. Sci. Appl., 3, 45 (2010).

30. M.M. Ba-Abbad, A.H. Kadhum, A.B. Mohamad, M.S. Takriff and K. Sopian, J. Alloys Comp., 550, 63 (2013). 